\title{
Clinico-pathological characteristics and outcomes of patients with biopsy-proven hypertensive nephrosclerosis: a retrospective cohort study
}

\author{
Shaoshan Liang*, Weibo Le, Dandan Liang, Hao Chen, Feng Xu, Huiping Chen, Zhihong Liu and Caihong Zeng*
}

\begin{abstract}
Background: This study aimed to investigate renal outcomes and their predictors in biopsy-proven hypertensive nephrosclerosis (HN) patients and to compare clinico-pathological characteristics and prognoses between benign nephrosclerosis (BN) and malignant nephrosclerosis (MN) patients.

Methods: Data for biopsy-proven HN patients were retrospectively analyzed. Renal survival rates and relationships between clinico-pathological characteristics and outcomes were assessed.

Results: A total of 194 patients were enrolled; the mean age at biopsy was 43.8 years, and male gender predominated $(82.5 \%)$. The median duration of hypertension was 5.0 years, and the mean systolic and diastolic blood pressures were $195 \pm 37$ and $126 \pm 26 \mathrm{mmHg}$, respectively. The median serum creatinine (Scr) level, estimated glomerular filtration rate (eGFR), and proteinuria level were $1.61 \mathrm{mg} / \mathrm{dl}, 49.6 \mathrm{ml} / \mathrm{min} / 1.73 \mathrm{~m}^{2}$, and $0.80 \mathrm{~g} / 24 \mathrm{~h}$, respectively. BN and MN were found by renal biopsy in $55.2 \%$ and $44.8 \%$ of patients, respectively. At biopsy, MN patients were younger, and had higher median Scr and proteinuria levels, higher incidences of anemia, hypertensive heart disease and hypertensive retinopathy, and worse renal outcomes than BN patients. During a median follow-up period of 3.0 years, 36 patients (18.6\%) reached end-stage renal disease (ESRD), and the 5- and 10-year cumulative renal survival rates for HN patients were $84.5 \%$ and $48.9 \%$, respectively. A decreased baseline eGFR, an increased baseline proteinuria level, anemia, increased percentage of global glomerulosclerosis and tubular atrophy and interstitial fibrosis (TAIF) were independent predictors of future ESRD.

Conclusions: The clinico-pathological characteristics and prognoses were significantly different between the MN and BN patients. The renal outcomes of HN patients were independently associated with the baseline eGFR and proteinuria level, anemia, percentage of global glomerulosclerosis and TAIF.
\end{abstract}

Keywords: Hypertension, Benign nephrosclerosis, Malignant nephrosclerosis, Risk factors, Renal survival

\section{Background}

Hypertension is a worldwide public health challenge due to its high prevalence, occurring in up to $26 \%$ of the adult population [1], and the concomitant risks of cardiovascular, cerebrovascular and kidney disease. Hypertensive nephrosclerosis ( $\mathrm{HN})$ is a common risk factor for end-stage renal disease (ESRD) in developed countries,

\footnotetext{
*Correspondence: southerns007@126.com; zengch_nj@hotmail.com
National Clinical Research Center of Kidney Diseases, Jinling Hospital, Nanjing

*Correspondence: southerns007@126.com; zengch_nj@hotmail.com University School of Medicine, East 305 Zhongshan Road, Nanjing, Jiangsu 210002, China
}

accounting for 3.3-23.4 \% of ESRD patients in Europe (according to the ERA-EDTA Registry Annual Report, (1) $30.5 \%$ of ESRD patients in the US [2]. The in country because of the large population.

Usually, a diagnosis of $\mathrm{HN}$ is assigned based on clinical manifestations. Most studies of HN have focused on the clinical predictors of renal disease progression, including race $[4,5]$, blood pressure [6-9], renal dysfunction [elevated serum creatinine (Scr) level or decreased 
estimated glomerular filtration rate (eGFR)] [6, 10-13], proteinuria $[10,11]$, and concomitant cardiovascular disease $[11,14,15]$. Hypertension is divided into benign hypertension and malignant hypertension, and renal damage from these types of hypertension is categorized as benign nephrosclerosis (BN) and malignant nephrosclerosis $(\mathrm{MN})$, respectively. Long-term renal outcomes are much worse in patients with malignant hypertension $[16,17]$ than in those with benign hypertension [4]. Renal biopsy is useful for the differential diagnosis between HN and primary glomerulonephritis with hypertension [18-20], but only a limited number of studies of biopsy-proven $\mathrm{HN}$ have focused on long-term renal outcomes and negative prognostic factors [10-13, 21, 22].

We analyzed data from adult Chinese patients with biopsy-proven $\mathrm{HN}$ to investigate the clinico-pathological characteristics and to evaluate the long-term renal survival rates and related risk factors for progression to ESRD. In addition, the clinico-pathological characteristics and prognoses between patients with $\mathrm{BN}$ and $\mathrm{MN}$ were compared.

\section{Methods}

\section{Study population}

The clinical and renal histopathological data of patients with biopsy-proven $\mathrm{HN}$ in Jinling Hospital, Nanjing, from January 2003 to June 2013 were retrospectively reviewed. During the study period, the total number of native kidney biopsies was 31594, from which 411 patients $(1.3 \%)$ with a diagnosis of $\mathrm{HN}$ were identified. The inclusion criteria were as follows: (1) evidence of hypertension before the detection of proteinuria, hematuria and/or impaired renal function; (2) evidence of $\mathrm{HN}$ on renal histology; (3) the lack of any clinical, immunological or histological evidence of other glomerular disease or systemic disorder, such as glomerulonephritis or diabetic nephropathy, and the lack of any defined cause of thrombotic microangiopathy such as hemolytic uremic syndrome or thrombotic thrombocytopenic purpura; (4) an age of between 18 and 65 years; (5) a follow-up period of $\geq 1.0$ year or reaching ESRD within 1 year; and (6) the availability of adequate biopsies ( $\geq 8$ glomeruli). A total of 194 patients were included in this study.

Indications for renal biopsies included proteinuria $(>0.4 \mathrm{~g} / 24 \mathrm{~h}$ ), hematuria (urine sediment red cell count $>100,000 \mathrm{cells} / \mathrm{ml}$ ) and/or impaired renal function. Renal biopsies were performed after adequate blood pressure control was achieved.

\section{Clinical and laboratory parameters}

The baseline and follow-up data of the patients were obtained by retrospective chart review. The data included gender, age, family history of hypertension, hypertension duration, systolic blood pressure (SBP), diastolic blood pressure (DBP), smoking status, Scr, and uric acid levels, anemia (male: hemoglobin $<120 \mathrm{~g} / \mathrm{L}$, female: hemoglobin $<110 \mathrm{~g} / \mathrm{L}$ ), elevated lactate dehydrogenase $(\mathrm{LDH})(\mathrm{LDH}>240 \mathrm{U} / \mathrm{L})$, thrombocytopenia (platelets < $\left.100 \times 10^{9} / \mathrm{L}\right)$, 24 -h urinary protein excretion, microscopic hematuria, hypertensive heart disease, cerebrovascular disease, and retinopathy (using the KeithWagener-Barker criteria). The eGFR was calculated using the Chronic Kidney Disease Epidemiology Collaboration (CKD-EPI) equation. Mean arterial pressure (MAP) was defined as the diastolic pressure plus one third of the pulse pressure. For each patient, the highest blood pressure before biopsy and the time-average blood pressure during follow-up, which was defined as the ratio of the area under the curve of MAP during follow-up to the duration of the follow-up [23], were recorded. The number of antihypertensive medications taken during the follow-up period was collected, and oral antihypertensive drugs were categorized into the following classes: angiotensin-converting enzyme inhibitors (ACEIs) and/or angiotensin receptor blockers (ARBs), calcium channel blockers (CCBs), beta blockers (BBs), diuretics and others. Patients were censored at the start of renal replacement therapy or loss to follow-up.

\section{Renal histopathology}

The tissue for light microscopy was serially sectioned, using hematoxylin and eosin, periodic acidSchiff, methenamine-silver, and Masson trichrome stains. Cryosections were stained with fluorescein isothiocyanate-conjugated rabbit anti-human immunoglobulin G (IgG), IgA, IgM, complement 3 (C3), and C1q. Paraffin sections were stained with fibrinogen. The tissue for electron microscopy was processed according to standard protocols. All biopsy slides were re-reviewed by two pathologists (Dr. Shaoshan Liang and Dr. Dandan Liang) without knowledge of the clinical outcomes. A senior pathologist (Dr. Caihong Zeng) reviewed the slides and made the final decision in cases of disagreement.

$\mathrm{HN}$ was divided into two pathological patterns, BN and $\mathrm{MN}$. BN was characterized by arterial or arteriolar hyalinosis, intimal fibrosis, or medial hypertrophy. $\mathrm{MN}$ was characterized by fibrinoid necrosis (acute stage) or myointimal cell proliferation, usually with an "onionskinning" appearance (chronic stage). Samples of concurrent $\mathrm{MN}$ and $\mathrm{BN}$ lesions were placed into the $\mathrm{MN}$ group. The arteries and arterioles were semiquantitatively evaluated for hyalinosis on a scale of $0-2+(0$, absent; $1+$, present, nonocclusive of lumen; $2+$, present, extensive, and/or impinging on lumen); intimal fibrosis on a scale of $0-4+(0$, no lesions; $1+$, minimally recognizable intimal fibrosis; $2+$, intimal fibrosis with $<25 \%$ luminal occlusion; $3+$, intimal fibrosis with $26-50 \%$ 
luminal occlusion; 4+, advanced lesions with >50 \% luminal occlusion); and medial hypertrophy on a scale of $0-2+(0$, absent; $1+$, minimal to mild; $2+$, moderate to severe). The extents of global glomerulosclerosis, segmental glomerulosclerosis, and glomerular ischemia were expressed as percentages of the total glomeruli. The morphological classification of focal segmental glomerulosclerosis (FSGS) was based on the Columbia classification [24]. The severity of tubular atrophy and interstitial fibrosis (TAIF) was semiquantitatively scored as the percentage of the renal cortical area involvement.

\section{Outcome}

The primary outcome of this study was ESRD, which was defined as eGFR $<15 \mathrm{ml} / \mathrm{min} / 1.73 \mathrm{~m}^{2}$, the initiation of chronic renal replacement therapy, or transplantation.

\section{Statistical analysis}

Normally distributed variables were expressed as the mean \pm SD and compared using Student's $t$-test. Nonparametric variables were expressed as medians [interquartile ranges (IQRs)] and compared using the Mann-Whitney-Wilcoxon test. Categorical variables were expressed as the number of positive cases (percentages) and compared using the Pearson $\chi^{2}$ test. The reproducibility of the pathology variables was evaluated using intraclass correlation coefficients (ICCs). Correlations between the pathology variables were analyzed using the Spearman test. The renal survival rates were estimated using the Kaplan-Meier method, and the log-rank test was used to assess the significance of differences in the Kaplan-Meier survival curves. The Cox proportional hazard model was used to explore the influences of the variables on the occurrence of ESRD. The pathological variables of poor reproducibility $(\mathrm{ICC}<0.40)$ were excluded from the model. The variables which were found to be significant $(P<0.05)$ by univariate analysis were included in the multivariate model using backward stepwise method. The assumption of Cox proportional hazards model were assessed using Schoenfeld residuals plots. All $\mathrm{P}$ values were two-tailed, and a $P<0.05$ was considered statistically significant. All analyses were performed using SPSS 18.0 software for Windows (SPSS Inc., Chicago, IL, USA) and $R$ software (version 3.2.1).

\section{Results}

\section{Clinical features}

This study included 194 patients who were predominantly male $(82.5 \%)$. The mean age at the time of biopsy was $43.8 \pm 4.1$ years. The median duration of hypertension was 5.0 years (IQR, 1.0-9.0). The mean SBP and DBP were $195 \pm 37$ and $126 \pm 26 \mathrm{mmHg}$, respectively. The median Scr level was $1.61 \mathrm{mg} / \mathrm{dl}$ (IQR, 1.24-2.27), the median eGFR was $49.6 \mathrm{ml} / \mathrm{min} / 1.73 \mathrm{~m}^{2}$ (IQR, 32.8$65.7)$, and the median proteinuria level was $0.80 \mathrm{~g} / 24 \mathrm{~h}$ (IQR, 0.42-1.48). During a median follow-up period of 3.0 years (IQR, 1.8-4.3), 36 patients (18.6\%) developed ESRD (Table 1), and the 5- and 10-year cumulative renal survival rates after renal biopsy, calculated using KaplanMeier method, were $84.5 \%$ and $48.9 \%$, respectively (Fig. 1). The average number of antihypertensive drugs taken during the follow-up period was $2.7 \pm 1.3$; and $88.7 \%$ of the patients were treated with ACEIs/ARBs, $75.8 \%$ were treated with CCBs, $49.0 \%$ were treated with BBs, and $20.6 \%$ were treated with diuretics.

\section{Comparisons of clinical features between the MN and BN groups}

MN was found in 87 patients (44.8\%), and $\mathrm{BN}$ was found in 107 (55.2 \%). The comparisons of the clinical features between the $\mathrm{BN}$ and $\mathrm{MN}$ groups are presented in Table 1. The patients with $\mathrm{MN}$ were younger, had a higher male: female ratio, had a shorter duration of hypertension and had higher blood pressure. The MN group had higher incidences of hypertensive heart disease and hypertensive retinopathy than the $\mathrm{BN}$ group.

The patients with $\mathrm{MN}$ exhibited more severe renal injuries, as indicated by higher median Scr, mean serum uric acid and median proteinuria levels, and a higher incidence of anemia, compared with those with BN.

Although the patients with $\mathrm{MN}$ received more antihypertensive medications, the time-average MAP was higher, and more patients progressed to ESRD than those with BN (Table 1). The 5- and 10-year cumulative renal survival rates after biopsy were $98.1 \%$ and $58.3 \%$, respectively, for the $\mathrm{BN}$ group, and $66.8 \%$ and $19.4 \%$, respectively, for the $\mathrm{MN}$ group (log-rank $P<0.001$ ) (Fig. 1).

\section{Comparisons of histological features between the MN and $\mathrm{BN}$ groups}

The patients with $\mathrm{MN}$ exhibited more severe medial hypertrophy, whereas those with BN exhibited a higher hyalinosis score. The intimal fibrosis score was not significantly different between the $\mathrm{MN}$ and $\mathrm{BN}$ groups. In general, the percentage of segmental glomerulosclerosis was significantly increased in the MN group compared with the BN group. Ninety patients presented with segmental glomerulosclerosis, 54 of which had the perihilar variant. And the MN group had a higher incidence of perihilar variant than the BN group (69.4\% vs. $48.8 \%$, $P=0.047)$. The percentage of ischemic glomeruli was significantly higher in the $\mathrm{MN}$ group than in the $\mathrm{BN}$ group, but the percentage of global glomerulosclerosis did not differ between two groups. The percentage of TAIF was significantly greater in the MN group than in the BN group (Table 2). 
Table 1 Comparisons of the clinical features between the MN and BN groups

\begin{tabular}{|c|c|c|c|c|}
\hline & $\begin{array}{l}\text { Total patients } \\
(n=194)\end{array}$ & $\begin{array}{l}\text { BN group } \\
(n=107)\end{array}$ & $\begin{array}{l}\text { MN group } \\
(n=87)\end{array}$ & $P$ \\
\hline \multicolumn{5}{|l|}{ At time of biopsy } \\
\hline Sex (male:female) & $160: 34$ & $81: 26$ & $79: 8$ & 0.006 \\
\hline Age (y) & $43.8 \pm 4.1$ & $47.4 \pm 10.3$ & $39.4 \pm 10.7$ & $<0.001$ \\
\hline Hypertension family history & $114(58.8 \%)$ & $59(55.1 \%)$ & $55(63.2 \%)$ & 0.26 \\
\hline Hypertension duration (y) & $5.0(1.0-9.0)$ & $6.0(2.4-10.0)$ & $3.0(0.2-7.0)$ & $<0.001$ \\
\hline $\mathrm{SBP}(\mathrm{mmHg})$ & $195 \pm 37$ & $182 \pm 32$ & $213 \pm 32$ & $<0.001$ \\
\hline $\mathrm{DBP}(\mathrm{mmHg})$ & $126 \pm 26$ & $119 \pm 23$ & $138 \pm 25$ & $<0.001$ \\
\hline MAP (mmHg) & $150 \pm 27$ & $139 \pm 24$ & $163 \pm 25$ & $<0.001$ \\
\hline Current smoker & $57(29.4 \%)$ & $30(28.0 \%)$ & $27(31.0 \%)$ & 0.65 \\
\hline \multicolumn{5}{|l|}{ Grades of retinopathy } \\
\hline$|-| \mid(\%)\left(n^{*}\right)$ & $73(50.3 \%)(145)$ & $44(58.7 \%)(75)$ & $29(41.4 \%)(70)$ & \multirow[t]{2}{*}{$<0.001$} \\
\hline III-IV (\%) $\left(n^{*}\right)$ & $42(29.0 \%)(145)$ & $8(10.7 \%)(75)$ & $34(48.6 \%)(70)$ & \\
\hline Hypertensive heart disease & $110(56.7 \%)$ & $42(39.3 \%)$ & $68(78.2 \%)$ & $<0.001$ \\
\hline Hypertensive cerebrovascular disease & $18(9.3 \%)$ & $12(11.2 \%)$ & $6(6.9 \%)$ & 0.30 \\
\hline $\mathrm{Scr}(\mathrm{mg} / \mathrm{dl})$ & $1.61(1.24-2.27)$ & $1.35(1.07-1.60)$ & $2.27(1.74-3.14)$ & $<0.001$ \\
\hline $\operatorname{eGFR}\left(\mathrm{ml} / \mathrm{min} / 1.73 \mathrm{~m}^{2}\right)$ & $49.6(32.8-65.7)$ & $60.5(48.9-76.5)$ & $34.5(24.2-46.8)$ & $<0.001$ \\
\hline $\mathrm{eGFR}<60 \mathrm{ml} / \mathrm{min} / 1.73 \mathrm{~m}^{2}$ & $130(67.0 \%)$ & $51(47.7 \%)$ & 79(90.8 \%) & $<0.001$ \\
\hline Uric acid $(\mu \mathrm{mol} / \mathrm{l})$ & $455 \pm 109$ & $437 \pm 111$ & $482 \pm 101$ & 0.004 \\
\hline Anemia & $36(18.6 \%)$ & $10(9.3 \%)$ & $26(29.9 \%)$ & $<0.001$ \\
\hline Elevated LDH & $5(2.6 \%)$ & $0(0 \%)$ & $5(5.7 \%)$ & - \\
\hline Thrombocytopenia & $1(0.5 \%)$ & $0(0 \%)$ & $1(1.1 \%)$ & - \\
\hline Proteinuria (g/24 h) & $0.80(0.42-1.48)$ & $0.72(0.38-1.34)$ & $0.89(0.58-1.57)$ & 0.02 \\
\hline Microscopic hematuria & $46(23.7 \%)$ & $31(29.0 \%)$ & $15(17.2 \%)$ & 0.06 \\
\hline \multicolumn{5}{|l|}{ Follow-up } \\
\hline No. of antihypertensive drugs & $2.7 \pm 1.3$ & $2.3 \pm 1.1$ & $3.3 \pm 1.2$ & $<0.001$ \\
\hline Time-average MAP $(\mathrm{mmHg})\left(\mathrm{n}^{*}\right)$ & $129 \pm 13(157)$ & $124 \pm 11(88)$ & $135 \pm 14(69)$ & $<0.001$ \\
\hline ESRD & $36(18.6 \%)$ & $7(6.5 \%)$ & $29(33.3 \%)$ & $<0.001$ \\
\hline
\end{tabular}

Data are presented as the medians $\left(25^{\text {th }}\right.$ and $75^{\text {th }}$ percentiles), the mean $\pm S D$, or the number of positive cases (percentages). $\mathrm{n}^{*}$ is the available $\mathrm{n}$ for a given value. Where not specified, the available $\mathrm{n}$ is the same as the total number of cases in the top row

$\mathrm{BN}$, benign nephrosclerosis; MN, malignant nephrosclerosis; SBP, systolic blood pressure; DBP, diastolic blood pressure; MAP, mean blood pressure; Scr, serum creatinine; eGFR, estimated glomerular filtration rate; LDH, lactate dehydrogenase; ESRD, end-stage renal disease

\section{Histological features of MN lesions}

Of the 87 patients in the MN group, the incidence of arteriolar involvement was $100 \%$, whereas that of arterial involvement was $44.0 \%$. Chronic MN lesions were observed in $94.3 \%$ of the patients in the MN group with arteriolar (81 cases) and arterial (37 cases) involvement. Acute MN lesions were observed in $37.9 \%$ of the patients in the MN group with arteriolar (33 cases) and arterial (1 case) involvement. Twenty-eight patients presented with both chronic and acute MN lesions. Only one case showed glomerular fibrinoid necrosis.

Reproducibility was assessed statistically using ICCs, which are summarized in Table 3.

Correlations between the pathology variables are shown in Additional file 1: Table S1.

\section{Clinical and pathological predictors of ESRD}

Table 4 shows the MN lesions and renal outcomes for the patients with preserved renal function vs. ESRD. The patients with chronic and acute MN lesions had a higher incidence of progression to ESRD than those with preserved renal function (77.8 \% vs. $34.2 \%, P<0.001$; $33.3 \%$ vs. $13.3 \%, P=0.004$, respectively). Based on the vessel size, the involvement of both arterioles and arteries in chronic MN lesions and the involvement of arterioles in acute MN lesions were associated with ESRD.

The univariate Cox regression analysis indicated that the baseline eGFR [hazard ratio (HR), 0.42, $95 \%$ confidence interval $(\mathrm{CI}), 0.32-0.56$ per $10 \mathrm{ml} / \mathrm{min} / 1.73 \mathrm{~m}^{2}$ increase, $P<0.001$ ], baseline proteinuria (HR, 2.27, $95 \%$ $\mathrm{CI}, 1.70-3.02$ per $1 \mathrm{~g} / 24 \mathrm{~h}$ increase, $P<0.001)$, anemia 


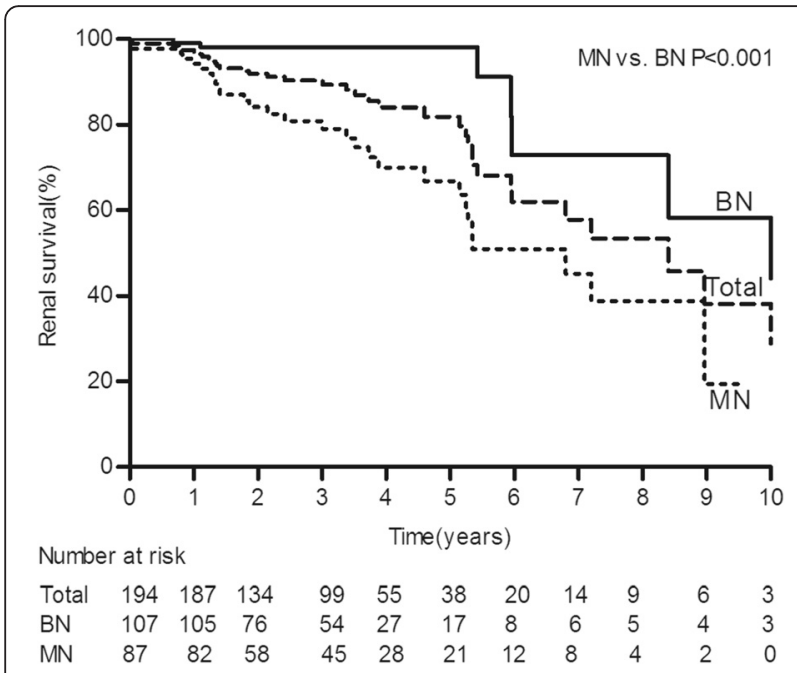

Fig. 1 Kaplan-Meier renal survival curves for 194 patients with HN. The 5- and 10-year cumulative renal survival rates after biopsy were $84.5 \%$ and $48.9 \%$, respectively, for 194 patients with HN. The 5- and 10-year cumulative renal survival rates after biopsy were $98.1 \%$ and $58.3 \%$, respectively, for the BN group, and $66.8 \%$ and $19.4 \%$, respectively, for the $M N$ group (log-rank $P<0.001)$. HN, hypertensive nephrosclerosis; BN, benign nephrosclerosis; MN, malignant nephrosclerosis

(HR, 4.18, 95 \% CI, 2.10-8.33, $P<0.001$ ), hyperuricemia (HR, 2.31, $95 \% \mathrm{CI}, 1.08-4.93, P=0.03$ ), the percentage of global glomerulosclerosis (HR, 1.44, $95 \% \mathrm{CI}, 1.23$ 1.70 per $10 \%$ increase, $P<0.001$ ), percentage of segmental glomerulosclerosis (HR, 2.02, $95 \%$ CI, 1.31-3.12 per $10 \%$ increase, $P=0.001$ ), percentage of TAIF (HR, 1.83, $95 \% \mathrm{CI}, 1.48-2.25$ per $10 \%$ increase, $P<0.001)$, and the presence of $\mathrm{MN}(\mathrm{HR}, 5.51,95 \% \mathrm{CI}, 2.27-13.33$, $P<0.001$ ) were associated with renal outcome (Table 5). These parameters were then considered in the multivariate Cox proportional hazards model, which showed that the baseline eGFR (HR, 0.55, $95 \% \mathrm{CI}, 0.39-0.77$ per $10 \mathrm{ml} / \mathrm{min} / 1.73 \mathrm{~m}^{2}$ increase, $P<0.001$ ), baseline proteinuria $(\mathrm{HR}, 1.54,95 \% \mathrm{CI}, 1.07-2.21$ per $1 \mathrm{~g} / 24 \mathrm{~h}$
Table 3 ICCS of the HN patients

\begin{tabular}{ll}
\hline & ICC \\
\hline Acute MN lesions & 0.66 \\
Chronic MN lesions & 0.63 \\
Hyalinosis & 0.57 \\
Intimal fibrosis & 0.64 \\
Medial hypertrophy & 0.40 \\
Global glomerulosclerosis (\%) & 0.98 \\
Segmental glomerulosclerosis (\%) & 0.94 \\
Ischemic glomeruli (\%) & 0.71 \\
TAIF (\%) & 0.75 \\
\hline
\end{tabular}

Note: an ICC of less than 0.40 is poor reproducibility, $0.40-0.59$ is reproducibility, $0.60-0.79$ is substantial reproducibility, and $0.80-1$ is outstanding reproducibility MN, malignant nephrosclerosis; TAIF, tubular atrophy/interstitial fibrosis; ICC: intraclass correlation coefficient

increase, $P=0.02)$, anemia (HR, 2.28, $95 \% \mathrm{CI}$, 1.04-4.99, $P=0.04$ ), percentage of global glomerulosclerosis (HR, 1.33, $95 \% \mathrm{CI}, 1.12-1.58$ per $10 \%$ increase, $P=0.001)$ and percentage of TAIF (HR, 1.48, $95 \% \mathrm{CI}, 1.08-2.03, P=$ 0.02) were independent predictors of renal outcome (Table 6). Hyperuricemia, the percentage of segmental glomerulosclerosis and the presence of $\mathrm{MN}$ were not predictive of renal outcome independently.

\section{Discussion}

The incidence of hypertension significantly increased from 1991-2009 in China [25], and accordingly, hypertension-induced renal damage also increased. Based on the renal biopsy registry of Jinling Hospital, Nanjing, the incidence of $\mathrm{HN}$ increased from $0.45 \%$ in 1979-2002 [26] to $1.3 \%$ in 2003-2013, which was similar to the findings of a recent report from Japan (1.3\%) [27]. Therefore, HN might become a common risk factor for ESRD in China.

Hypertension is categorized as benign hypertension and malignant hypertension, and the renal damage caused by these types of hypertension is classified as $\mathrm{BN}$

Table 2 Comparisons of the histological features between the MN and BN groups

\begin{tabular}{|c|c|c|c|c|}
\hline & $\begin{array}{l}\text { Total patients } \\
(n=194)\end{array}$ & $\begin{array}{l}\text { BN group } \\
(n=107)\end{array}$ & $\begin{array}{l}\text { MN group } \\
(n=87)\end{array}$ & $P$ \\
\hline Hyalinosis & $1.09 \pm 0.67$ & $1.25 \pm 0.57$ & $0.90 \pm 0.73$ & $<0.001$ \\
\hline Intimal fibrosis $\left(\mathrm{n}^{*}\right)$ & $1.74 \pm 1.18(189)$ & $1.79 \pm 1.10(105)$ & $1.68 \pm 1.28(84)$ & 0.52 \\
\hline Medial hypertrophy & $0.69 \pm 0.65$ & $0.42 \pm 0.55$ & $1.01 \pm 0.62$ & $<0.001$ \\
\hline Global glomerulosclerosis (\%) & $30(18-46)$ & $32(18-45)$ & $28(18-50)$ & 0.63 \\
\hline Segmental glomerulosclerosis (\%) & $0(0-6)$ & $0(0-5)$ & $3(0-6)$ & 0.04 \\
\hline Ischemic glomeruli (\%) & $8(0-22)$ & $3(0-9)$ & $20(8-30)$ & $<0.001$ \\
\hline TAIF (\%) & $30(20-60)$ & $30(10-30)$ & $60(40-70)$ & $<0.001$ \\
\hline
\end{tabular}

Data are presented as the medians $\left(25^{\text {th }}\right.$ and $75^{\text {th }}$ percentiles), the mean \pm SD. $n^{*}$ is the available $n$ for a given value. Where not specified, the available $n$ is the same as the total number of cases in the top row

BN, benign nephrosclerosis; MN, malignant nephrosclerosis; TAIF, tubular atrophy/interstitial fibrosis 
Table 4 MN lesions and renal outcomes for patients with preserved renal function vs. ESRD

\begin{tabular}{llll}
\hline & $\begin{array}{l}\text { Preserved renal } \\
\text { function }(n=158)\end{array}$ & $\begin{array}{l}\text { ESRD } \\
(n=36)\end{array}$ & $P$ \\
\hline MN & $58(36.7 \%)$ & $29(80.6 \%)$ & $<0.001$ \\
Chronic lesions & $54(34.2 \%)$ & $28(77.8 \%)$ & $<0.001$ \\
Arteriolar involvement & $53(33.5 \%)$ & $28(77.8 \%)$ & $<0.001$ \\
Arterial involvement $\left(\mathrm{n}^{*}\right)$ & $22(14.3 \%)(154)$ & $15(42.9 \%)(35)$ & $<0.001$ \\
Acute lesions & $21(13.3 \%)$ & $12(33.3 \%)$ & 0.004 \\
Arteriolar involvement & $21(13.3 \%)$ & $12(33.3 \%)$ & 0.004 \\
Arterial involvement $\left(\mathrm{n}^{*}\right)$ & $0(0 \%)(154)$ & $1(2.9 \%)(35)$ & - \\
\hline
\end{tabular}

Data are presented as the number of positive cases (percentages). $n^{*}$ is the available $\mathrm{n}$ for a given value. Where not specified, the available $\mathrm{n}$ is the same as the total number of cases in the top row

$\mathrm{MN}$, malignant nephrosclerosis; ESRD, end-stage renal disease

and MN. MN was observed in $44.8 \%$ of 194 patients with biopsy-proven $\mathrm{HN}$ in the present study, which was nearly identical to that reported by Caetano et al. (43\%) [28] and was higher than those reported by other studies (10.3-12.8 \%) [20, 29]. The patients in our study were Chinese, whereas those in the other studies were Caucasian or African American. In Caetano's study [28], the average blood pressure was lower than that in the present study (SBP/DBP 183/117 mmHg vs. 195/ $126 \mathrm{mmHg})$, whereas the Scr level was higher $(3.28 \mathrm{mg} /$ dl vs. $1.61 \mathrm{mg} / \mathrm{dl}$ ). In Fogo's study [20], the average eGFR was higher than that in the present study $(51.1 \mathrm{ml} / \mathrm{min} /$ $1.73 \mathrm{~m}^{2}$ vs. $49.6 \mathrm{ml} / \mathrm{min} / 1.73 \mathrm{~m}^{2}$ ). The different incidences of MN in biopsy-proven $\mathrm{HN}$ may be associated with variations in ethnicity and patient inclusion criteria.

In the present study, the MN group was younger, displayed higher SBP and DBP levels, had higher median Scr, mean uric acid and median proteinuria levels, and had higher incidences of hypertensive heart disease and retinopathy at baseline than the BN group. In Caetano's series [28], the MN group was younger, displayed higher DBP and Scr levels, and had a higher incidence of

Table 5 Univariate Cox regression analyses of factors associated with renal survival

\begin{tabular}{lll}
\hline & $\mathrm{HR}(95 \% \mathrm{Cl})$ & $\mathrm{P}$ \\
\hline eGFR $^{\mathrm{a}}$ & $0.42(0.32-0.56)$ & $<0.001$ \\
Proteinuriab $^{\mathrm{b}}$ & $2.27(1.70-3.02)$ & $<0.001$ \\
Anemia $_{\text {Hyperuricemia }}$ & $4.18(2.10-8.33)$ & $<0.001$ \\
TAIF $^{c}$ & $2.31(1.08-4.93)$ & 0.03 \\
Global glomerulosclerosis $^{c}$ & $1.83(1.48-2.25)$ & $<0.001$ \\
Segmental glomerulosclerosis $^{c}$ & $1.44(1.23-1.70)$ & $<0.001$ \\
Presence of MN $^{2}$ & $2.02(1.31-3.12)$ & 0.001 \\
\hline
\end{tabular}

${ }^{a}$ per $10 \mathrm{ml} / \mathrm{min} / 1.73 \mathrm{~m}^{2}$ increase; ${ }^{b}$ per $1 \mathrm{~g} / 24 \mathrm{~h}$ increase; ${ }^{c}$ per $10 \%$ increase MN, malignant nephrosclerosis; TAIF, tubular atrophy/interstitial fibrosis; HR, hazard ratio; $\mathrm{Cl}$, confidence interval
Table 6 Multivariate Cox regression analyses of factors associated with renal survival

\begin{tabular}{lll}
\hline & $\mathrm{HR}(95 \% \mathrm{Cl})$ & $\mathrm{P}$ \\
\hline eGFR $^{\mathrm{a}}$ & $0.55(0.39-0.77)$ & $<0.001$ \\
Proteinuria $^{\mathrm{b}}$ & $1.54(1.07-2.21)$ & 0.02 \\
Anemia & $2.28(1.04-4.99)$ & 0.04 \\
TAIF $^{c}$ & $1.48(1.08-2.03)$ & 0.02 \\
Global glomerulosclerosis $^{c}$ & $1.33(1.12-1.58)$ & 0.001 \\
\hline
\end{tabular}

aper $10 \mathrm{ml} / \mathrm{min} / 1.73 \mathrm{~m}^{2}$ increase; ${ }^{\mathrm{b}}$ per $1 \mathrm{~g} / 24 \mathrm{~h}$ increase; ${ }^{c}$ per $10 \%$ increase

TAIF, tubular atrophy/interstitial fibrosis; $\mathrm{HR}$, hazard ratio; $\mathrm{Cl}$, confidence interval

hypertensive retinopathy than the $\mathrm{BN}$ group, whereas the uric acid and proteinuria levels were not different between the two groups. In Bohle's series [29], the MN group was younger and displayed higher SBP and DBP, and Scr and proteinuria levels than the $\mathrm{BN}$ group. In Ratschek's series [30], the MN group displayed higher SBP and DBP and Scr levels, whereas no difference in age was observed. Thus, the previous and present studies show that patients with $\mathrm{MN}$ are younger, have a higher Scr level and a higher incidence of hypertensive retinopathy, and have variable uric acid and proteinuria levels compared with those with $\mathrm{BN}$.

In the MN group, 5 patients had elevated LDH and 1 patient had thrombocytopenia at the time of biopsy. In previous retrospective studies of patients with malignant hypertension, $27-44 \%$ of patients have presented with thrombotic microangiopathy [16, 31, 32]. Microangiopathic hemolysis and thrombocytopenia have been reported to resolve within 3-21.7 days and 3-5 days, respectively, in patients with controlled blood pressure $[31,33]$. The low incidences of elevated LDH and thrombocytopenia in this study may have been due to the fact that the patients were receiving antihypertensive therapies and had controlled blood pressure on admission to our hospital.

Two pathological patterns based on the vascular lesion, $\mathrm{BN}$ and $\mathrm{MN}$, have been described as $\mathrm{HN}$. MN is characterized by fibrinoid necrosis (acute stage) and myointimal cell proliferation, usually with an "onionskinning" appearance (chronic stage). In the present study, the incidence of chronic-stage MN lesions was as high as $94.3 \%$ in the MN group, whereas that of acutestage $\mathrm{MN}$ lesions was low (37.9\% in the MN group). Furthermore, most patients with acute-stage MN lesions coexisted with chronic-stage MN lesions. These findings are similar to those of previous reports [30, 34]. The acute-stage $\mathrm{MN}$ lesions occurred during the more early stage of severe hypertension [34]. All these patients had to achieve adequate blood pressure control before biopsy because of the potential hazard of bleeding complications. The low incidence of acute-stage lesions might 
have been due to the severe hypertension in the more emergent patients serving as a contraindication of renal biopsy. Segmental fibrinoid necrosis of the glomerular tufts was perceived to be one of the characteristic lesions associated with malignant hypertension [35]. Nevertheless, glomerular fibrinoid necrosis was found in only one case in our study, and it was thus hard to evaluate its relationship with malignant hypertension.

The patients with MN presented with more severe histological lesions than those with BN. In agreement with previous studies $[29,30]$, the $M N$ group exhibited a higher percentage of ischemic glomeruli (MN vs. BN, $20 \%$ vs. $3 \%$ ). MN lesions led to marked narrowing or even occlusion of the lumen and caused the formation of ischemic glomeruli. Furthermore, the percentage of segmental glomerulosclerosis in the MN group was higher ( $\mathrm{MN}$ vs. $\mathrm{BN}, 3 \%$ vs. $0 \%$ ) and was predominantly of the perihilar type. These data may reflect the fact that the hyperfiltration status of the remaining nephron units was more severe in the $\mathrm{MN}$ group than in $\mathrm{BN}$ group [36]. The extent of TAIF was significantly higher in the MN group in our study, and previous studies have demonstrated that tubular atrophy and interstitial fibrosis are associated with reduced flow in peritubular capillaries, resulting in hypoxic damage $[37,38]$. The MN lesions caused narrowing of the lumen and reduced renal blood flow, leading to hypoxia and ultimately resulting in TAIF. Thus, we speculated that the MN lesions caused the devastating ischemic alterations that resulted in ischemia of glomeruli, segmental glomerulosclerosis, and TAIF. The MN group showed a higher medial hypertrophy score than the $\mathrm{BN}$ group in the present study, similar to the results of the study by Caetano [28]. Furthermore, our data showed that hyalinosis was more frequent in the $\mathrm{BN}$ group than in the $\mathrm{MN}$ group.

HN can lead to ESRD, as shown in Table 7, which summarizes the patient outcomes and prognostic indicators in our study as well as those in previous reports. In the present study, the 5- and 10-year cumulative renal survival rates after biopsy were $98.1 \%$ and $58.3 \%$, respectively, for the BN group. The 5- and 10-year renal survival rates of BN patients were respectively $80 \%$ and $72 \%$ in Norway [10], $56 \%$ and $35 \%$ in the UK [12], and $35.9 \%$ and $23.6 \%$ in Germany [13]. The patients in our study were younger and had lower baseline Scr levels than those in other studies. In addition, differences in ethnicity and changes in treatment strategies in recent decades might have contributed to the better renal outcomes observed in our study compared with previous studies. With the development of modern antihypertensive drugs, the prognosis of clinical malignant hypertension has improved. We reported the long-term renal outcome of biopsy-proven MN In this study, showing that during a median follow-up period of 3.0 years,
$33.3 \%$ of the patients progressed to ESRD in the MN group. Yu et al. reported that a series of MN patients, in which more severe renal involvement was observed, had a worse renal outcome ( $45.9 \%$ patients progressed to ESRD) during a mean follow-up period of 2.5 years than the present study [39] (Table 7).

The clinical parameters showed significant prognostic value for patients with $\mathrm{HN}$. Our study confirmed the baseline eGFR and proteinuria level as independent prognostic factors for progression to ESRD [10-13, 40]. In addition, anemia was found to be an independent prognostic factor for renal outcome. The serum uric acid level was higher in the $\mathrm{MN}$ group than in the $\mathrm{BN}$ group in our study. However, the presence of hyperuricemia, which predicted outcome in univariate Cox analysis, lost its prognostic value in multivariate Cox analysis. In the African American Study of Kidney Disease (AASK) cohort [11], the baseline hematocrit level was significantly associated with the risk for a GFR event or ESRD after adjustments for age, gender, baseline proteinuria, and baseline GFR, whereas no association was observed between serum uric acid level and renal outcome, which was similar to the findings of our study. Further prospective studies are required to confirm whether hyperuricemia is associated with renal outcomes for patients with $\mathrm{HN}$ in the Chinese population. Several studies have indicated that an increase in baseline blood pressure $[7,8]$, treatment-resistant hypertension $[6,9]$, and increases in SBP and DBP during follow-up $[12,16]$ are associated with an unfavorable outcome. In the present study, baseline blood pressure was not associated with renal outcome; however, these data are limited by the retrospective nature of this study. Prospective studies are needed to confirm the optimal blood pressure control strategy for patients with HN. Additionally, several studies have indicated that concomitant cardiovascular disease is associated with renal outcome [11, 14, 15]; however, no such associations were observed in the current series of patients.

Some pathological parameters were identified to predict renal outcome. TAIF was one of the prognostic factors identified in the present study that has also been reported as a factor for other renal diseases [41]. Global glomerulosclerosis also exhibited a significant negative prognostic influence in our study. Interestingly, the optimal cutoff of the percentage of global glomerulosclerosis for predicting renal outcome obtained by receiver operating characteristic (ROC) curve analysis was $40 \%$ (data not shown), which was nearly the same as the value obtained from a series of patients with biopsy-proven $\mathrm{BN}$ in Japan, in which global glomerulosclerosis (>41 \%) at biopsy was found to be an indicator of poor prognosis [21]. These findings suggest that global glomerulosclerosis has a negative prognostic impact on patients with 
Table 7 Renal outcomes and prognostic indicators for patients with biopsy-proven HN in the present study and in previous reports

\begin{tabular}{|c|c|c|c|c|c|c|c|c|c|}
\hline & Case numbers & Sex (male:female) & Age (y) & Scr (eGFR) & $\begin{array}{l}\text { Proteinuria } \\
\text { (g/24 h) }\end{array}$ & $\mathrm{BP}(\mathrm{mmHg})$ & $\begin{array}{l}\text { Duration of } \\
\text { follow-up (y) }\end{array}$ & Renal outcomes & Predictors of renal survival \\
\hline Takebayashi [21] & 590 & $2.5: 1$ & 56.5 & 1.90(ND) & ND & 154(SBP)87(DBP) & 10.1 & $\begin{array}{l}49.2 \% \text { of } 345 \text { cases reached } \\
\text { endpoint event ( } \mathrm{Scr} \geq 3 \mathrm{mg} / \mathrm{dl})\end{array}$ & $\begin{array}{l}\text { Poor or no control of BP, global } \\
\text { glomerulosclerosis }(>40 \%), \\
\text { presence of collapsed } \\
\text { glomeruli and/or segmental } \\
\text { glomerulosclerosis }\end{array}$ \\
\hline Marcantoni [22] & $62^{\mathrm{a}}$ & $1.3: 1$ & 58.7 & $3.40(\mathrm{ND})$ & 1.8 & $105 \pm 3(\mathrm{MAP})$ & 1.9 & $\begin{array}{l}47.8 \% \text { of } 23 \text { cases reached } \\
\text { ESRD }\end{array}$ & ND \\
\hline Wehrmann [13] & 170 & $5.0: 1$ & ND & ND & ND & ND & ND & $\begin{array}{l}\text { 5- and } 10 \text {-year renal survival } \\
\text { rates were } 35.9 \% \text { and } 23.6 \% \text {, } \\
\text { respectively }\end{array}$ & Baseline Scr \\
\hline Vikse [10] & 102 & 2.0:1 & 55.4 & $1.87(\mathrm{ND})$ & 0.4 & $\begin{array}{l}156 \pm 28(\mathrm{SBP}) \\
92 \pm 14(\mathrm{DBP})\end{array}$ & 11.7 & $\begin{array}{l}\text { 5- and } 10 \text {-year renal survival } \\
\text { rates were } 80 \% \text { and } 72 \% \text {, } \\
\text { respectively }\end{array}$ & Baseline Scr, proteinuria \\
\hline Norris [11] & $1094^{a}$ & $1.6: 1$ & 54.6 & $\mathrm{ND}(46.4)$ & 0.3 & $\begin{array}{l}150 \pm 24(\mathrm{SBP}) \\
96 \pm 14(\mathrm{DBP})\end{array}$ & 3.9 & $\begin{array}{l}13.1 \% \text { reached endpoint event } \\
\left(50 \% \text { or } 25 \mathrm{ml} / \mathrm{min} \text { per } 1.73 \mathrm{~m}^{2}\right. \\
\text { decline in GFR or ESRD) }\end{array}$ & $\begin{array}{l}\text { Baseline proteinuria, GFR, Scr,urea } \\
\text { nitrogen, phosphorus }\end{array}$ \\
\hline Dasgupta [12] & 60 & 2.0:1 & 58.0 & $2.79(36.0)$ & 2.3 & $\begin{array}{l}179 \pm 25(\mathrm{SBP}) \\
105 \pm 15(\mathrm{DBP})\end{array}$ & 6.7 & $\begin{array}{l}5 \text { - and } 10 \text {-year renal survival } \\
\text { rates were } 56 \% \text { and } 35 \% \text {, } \\
\text { respectively }\end{array}$ & $\begin{array}{l}\text { Baseline Scr, mean SBP and DBP } \\
\text { during follow-up (univariate } \\
\text { analysis), DBP during follow-up } \\
\text { (multivariate analysis) }\end{array}$ \\
\hline Yu [39] & 61 & $9.2: 1$ & 32.0 & 6.33(ND) & 3.46 & ND & 2.5 & 45.9 \% reached ESRD & ND \\
\hline This study & 194 & $4.7: 1$ & 43.8 & $1.61(49.6)$ & 0.80 & $\begin{array}{l}195 \pm 37(\mathrm{SBP}) \\
126 \pm 26(\mathrm{DBP})\end{array}$ & 3.0 & $\begin{array}{l}\text { 5- and } 10 \text {-year renal survival } \\
\text { rates were } 84.5 \text { and } 48.9 \% \text {, } \\
\text { respectively }\end{array}$ & $\begin{array}{l}\text { Baseline eGFR, proteinuria, } \\
\text { anemia, the percentage of global } \\
\text { glomerulosclerosis and TAIF }\end{array}$ \\
\hline
\end{tabular}

${ }^{a}$ Most cases underwent renal biopsies

ND, no data; BP, blood pressure; MAP, mean blood pressure; SBP, systolic blood pressure; DBP, diastolic blood pressure; MN, malignant nephrosclerosis; Scr, serum creatinine; eGFR, estimated glomerular filtration rate; ESRD, end-stage renal disease; TAIF, tubular atrophy/interstitial fibrosis 
both $\mathrm{BN}$ and $\mathrm{MN}$. Correlation analysis of pathology variables demonstrated that there was a strong correlation between the presence of $\mathrm{MN}$ and the percentage of TAIF $(r=0.643)$. Thus, the presence of MN predicted the risk for progression to ESRD in univariate Cox analysis, but lost its prognostic value in multivariate Cox analysis.

The limitations of this study must be recognized. The major limitation in this study is its retrospective nature. We cannot rule out the influence of selection bias because some patients, especially those only very mild cases, were unwilling to undergo renal biopsy when $\mathrm{HN}$ was diagnosed according to the clinical criteria. In addition, data on patient deaths were incomplete and the candidate factors associated with death were not assessed in this study.

\section{Conclusions}

Our results indicated that patients with $\mathrm{MN}$ and $\mathrm{BN}$ exhibited significantly different clinico-pathological characteristics. The MN group presented with more severe renal involvement and higher incidences of hypertensive heart disease and retinopathy, received more antihypertensive medications, and had poorer renal outcomes than the BN group. A decreased baseline eGFR, an increased baseline proteinuria level, anemia, increased percentage of global glomerulosclerosis and TAIF were associated with unfavorable renal outcomes in the patients with biopsy-proven $\mathrm{HN}$.

\section{Ethics approval}

The study was approved by the Ethics Committee of Jinling Hospital. No additional administrative permissions were necessary in order to access the clinical and renal histopathological data.

\section{Data availability statement}

All data underlying the findings are within the paper and the supporting information file (Additional file).

\section{Additional file}

Additional file 1: Table S1. Correlations between pathology variables. (DOC $45 \mathrm{~kb}$ )

\footnotetext{
Abbreviations

ACEls: angiotensin-converting enzyme inhibitors; ARBs: angiotensin receptor blockers; BBs: beta blockers; BN: benign nephrosclerosis; CCBs: calcium channel blockers; Cl: confidence interval; CKD-EPI: chronic kidney disease epidemiology collaboration; DBP: diastolic blood pressure; eGFR: estimated glomerular filtration rate; ESRD: end-stage renal disease; FSGS: focal segmental glomerulosclerosis; HN: hypertensive nephrosclerosis; HR: hazard ratio; ICC: intraclass correlation coefficient; IQR: interquartile range; LDH: lactate dehydrogenase; MAP: mean arterial pressure; MN: malignant nephrosclerosis; ND: no data; ROC: receiver operating characteristic; SBP: systolic blood pressure; Scr: serum creatinine; TAIF: tubular atrophy and interstitial fibrosis.
}

\section{Competing interests}

All authors declare that they have no competing interests.

\section{Authors' contributions}

SL carried out the clinico-pathological studies and drafted the manuscript. WL, HC and FX participated in patient inclusion and demographic data collection. CZ, SL and DL participated in the renal pathology studies. WL and $\mathrm{SL}$ participated in statistical analysis. ZL and CZ contributed to the conception and design of the study and revised the manuscript. H-PC helped to revise the manuscript. All authors read and approved the final manuscript.

\section{Acknowledgements}

This work was supported by Clinical Research Program of Jiangsu Province (No. BL2012007). We thank Professor Yang Zhao at the School of Public Health, Nanjing Medical University for his kind help in the statistical analysis of this paper.

Received: 29 December 2014 Accepted: 5 April 2016

Published online: 11 April 2016

\section{References}

1. Kearney PM, Whelton M, Reynolds K, Muntner P, Whelton PK, He J. Global burden of hypertension: analysis of worldwide data. Lancet. 2005;365(9455):217-23.

2. U.S. Renal Data System, USRDS 2013 Annual Data Report. Atlas of Chronic Kidney Disease and End-Stage Renal Disease in the United States. Bethesda, MD: National Institutes of Health, National Institute of Diabetes and Digestive and Kidney Diseases; 2013.

3. Reynolds K, Gu D, Muntner P, Kusek JW, Chen J, Wu X, Duan X, Chen CS, Klag MJ, Whelton PK, et al. A population-based, prospective study of blood pressure and risk for end-stage renal disease in China. J Am Soc Nephrol. 2007;18(6):1928-35.

4. Klag MJ, Whelton PK, Randall BL, Neaton JD, Brancati FL, Stamler J. End-stage renal disease in African-American and white men. 16-year MRFIT findings. JAMA. 1997;277(16):1293-8.

5. Shulman NB, Ford CE, Hall WD, Blaufox MD, Simon D, Langford HG, Schneider KA. Prognostic value of serum creatinine and effect of treatment of hypertension on renal function. Results from the hypertension detection and follow-up program. The Hypertension Detection and Follow-up Program Cooperative Group. Hypertension. 1989;13(5 Suppl):180-93.

6. Tanner RM, Calhoun DA, Bell EK, Bowling CB, Gutierrez OM, Irvin MR, Lackland DT, Oparil S, McClellan W, Warnock DG, et al. Incident ESRD and treatment-resistant hypertension: the reasons for geographic and racial differences in stroke (REGARDS) study. Am J Kidney Dis. 2014;63(5):781-8.

7. Tozawa M, Iseki K, Iseki C, Kinjo K, Ikemiya Y, Takishita S. Blood pressure predicts risk of developing end-stage renal disease in men and women. Hypertension. 2003;41(6):1341-5.

8. Perry Jr HM, Miller JP, Fornoff JR, Baty JD, Sambhi MP, Rutan G, Moskowitz DW, Carmody SE. Early predictors of 15-year end-stage renal disease in hypertensive patients. Hypertension. 1995;25(4 Pt 1):587-94.

9. De Nicola L, Gabbai FB, Agarwal R, Chiodini P, Borrelli S, Bellizzi V, Nappi F, Conte G, Minutolo R. Prevalence and prognostic role of resistant hypertension in chronic kidney disease patients. J Am Coll Cardiol. 2013; 61(24):2461-7.

10. Vikse BE, Aasarod K, Bostad L, Iversen BM. Clinical prognostic factors in biopsy-proven benign nephrosclerosis. Nephrol Dial Transplant. 2003;18(3):517-23.

11. Norris KC, Greene T, Kopple J, Lea J, Lewis J, Lipkowitz M, Miller P, Richardson A, Rostand S, Wang $X$, et al. Baseline predictors of renal disease progression in the African American Study of Hypertension and Kidney Disease. J Am Soc Nephrol. 2006;17(10):2928-36.

12. Dasgupta I, Porter C, Innes A, Burden R. "Benign" hypertensive nephrosclerosis. QJM. 2007;100(2):113-9.

13. Wehrmann M, Bohle A. The long-term prognosis of benign nephrosclerosis accompanied by focal glomerulosclerosis and renal cortical interstitial fibrosis, designated so-called decompensated benign nephrosclerosis by Fahr, Bohle and Ratscheck. Pathol Res Pract. 1998;194(8):571-6.

14. McClellan WM, Langston RD, Presley R. Medicare patients with cardiovascular disease have a high prevalence of chronic kidney disease and a high rate of progression to end-stage renal disease. J Am Soc Nephrol. 2004;15(7):1912-9. 
15. Marin R, Gorostidi M, Fernandez-Vega F, Alvarez-Navascues R. Systemic and glomerular hypertension and progression of chronic renal disease: the dilemma of nephrosclerosis. Kidney Int Suppl. 2005;99:S52-56.

16. Amraoui $F$, Bos $S$, Vogt $L$, van den Born BJ. Long-term renal outcome in patients with malignant hypertension: a retrospective cohort study. BMC Nephrol. 2012;13:71

17. Gonzalez R, Morales E, Segura J, Ruilope LM, Praga M. Long-term renal survival in malignant hypertension. Nephrol Dial Transplant. 2010;25(10):3266-72

18. Zucchelli P, Zuccala A. Progression of renal failure and hypertensive nephrosclerosis. Kidney Int Suppl. 1998;68:S55-59.

19. Zarif L, Covic A, lyengar S, Sehgal AR, Sedor JR, Schelling JR. Inaccuracy of clinical phenotyping parameters for hypertensive nephrosclerosis. Nephrol Dial Transplant. 2000;15(11):1801-7.

20. Fogo A, Breyer JA, Smith MC, Cleveland WH, Agodoa L, Kirk KA, Glassock R. Accuracy of the diagnosis of hypertensive nephrosclerosis in African Americans: a report from the African American Study of Kidney Disease (AASK) Trial. AASK Pilot Study Investigators. Kidney Int. 1997;51(1):244-52.

21. Takebayashi S, Kiyoshi Y, Hisano S, Uesugi N, Sasatomi Y, Meng J, Sakata N. Benign nephrosclerosis: incidence, morphology and prognosis. Clin Nephrol. 2001:55(5):349-56.

22. Marcantoni C, Ma LJ, Federspiel C, Fogo AB. Hypertensive nephrosclerosis in African Americans versus Caucasians. Kidney Int. 2002;62(1):172-80.

23. Le W, Liang S, Hu Y, Deng K, Bao H, Zeng C, Liu Z. Long-term renal survival and related risk factors in patients with IgA nephropathy: results from a cohort of 1155 cases in a Chinese adult population. Nephrol Dial Transplant. 2012;27(4):1479-85.

24. D'Agati VD, Fogo AB, Bruijn JA, Jennette JC. Pathologic classification of focal segmental glomerulosclerosis: a working proposal. Am J Kidney Dis. 2004:43(2):368-82.

25. Liang Y, Liu R, Du S, Qiu C. Trends in incidence of hypertension in Chinese adults, 1991-2009: The China Health and Nutrition Survey. Int J Cardiol. 2014.

26. Li LS, Liu ZH. Epidemiologic data of renal diseases from a single unit in China: analysis based on 13,519 renal biopsies. Kidney Int. 2004;66(3):920-3.

27. Sugiyama H, Yokoyama H, Sato H, Saito T, Kohda Y, Nishi S, Tsuruya K, Kiyomoto $H$, lida $H$, Sasaki $T$, et al. Japan renal biopsy registry and Japan kidney disease registry: committee report for 2009 and 2010. Clin Exp Nephrol. 2013;17(2):155-73

28. Caetano ER, Zatz R, Saldanha LB, Praxedes JN. Hypertensive nephrosclerosis as a relevant cause of chronic renal failure. Hypertension. 2001;38(2):171-6.

29. Bohle A, Wehrmann M, Greschniok A, Junghans R. Renal morphology in essential hypertension: analysis of 1177 unselected cases. Kidney Int Suppl. 1998;67:S205-206

30. Ratschek M, Ratschek E, Bohle A. Decompensated benign nephrosclerosis and secondary malignant nephrosclerosis. Clin Nephrol. 1986;25(5):221-6.

31. Akimoto T, Muto S, Ito C, Takahashi H, Takeda S, Ando Y, Kusano E. Clinical features of malignant hypertension with thrombotic microangiopathy. Clin Exp Hypertens. 2011;33(2):77-83.

32. van den Born BJH, Honnebier UPF, Koopmans RP, van Montfrans GA. Microangiopathic hemolysis and renal failure in malignant hypertension. Hypertension. 2004;45(2):246-51.

33. Nzerue C, Oluwole K, Adejorin D, Paueksakon P, Fremont R, Akatue R, Faulkner M. Malignant hypertension with thrombotic microangiopathy and persistent acute kidney injury (AKI). Clinical kidney journal. 2014:7(6):586-9.

34. Pitcock JA, Johnson JG, Hatch FE, Acchiardo S, Muirhead EE, Brown PS. Malignant hypertension in blacks. Malignant intrarenal arterial disease as observed by light and electron microscopy. Hum Pathol. 1976;7(3):333-46.

35. Laszik ZG, Silva FG. Hemolytic Uremic Syndrome, Thrombotic Thrombocytopenic Purpura, and Other Thrombotic Microangiopathies. In: Jennette JC, Olson JL, Schwartz MM, Silva FG, editors. Hepinstall's Pathology of the Kidney, vol. 1. 6th ed. Philadelphia: Lippincott Williams \& Wilkins; 2007. p. 701-64.

36. Luke RG. Hypertensive nephrosclerosis: pathogenesis and prevalence. Essential hypertension is an important cause of end-stage renal disease. Nephrol Dial Transplant. 1999;14(10):2271-8.

37. Nangaku M. Chronic hypoxia and tubulointerstitial injury: a final common pathway to end-stage renal failure. J Am Soc Nephrol. 2006;17(1):17-25.

38. Fine LG, Orphanides C, Norman JT. Progressive renal disease: the chronic hypoxia hypothesis. Kidney Int Suppl. 1998;65:S74-78.
39. Yu XJ, Yu F, Song D, Wang SX, Song Y, Liu G, Zhao MH. Clinical and renal biopsy findings predicting outcome in renal thrombotic microangiopathy: a large cohort study from a single institute in China. The Scientific World Journal. 2014;2014:680502.

40. Gudbrandsson T, Hansson L, Herlitz H, Andren L. Malignant hypertensionimproving prognosis in a rare disease. Acta medica Scandinavica. 1979; 206(6):495-9.

41. Zeng CH, Le W, Ni Z, Zhang M, Miao L, Luo P, Wang R, Lv Z, Chen J, Tian J, et al. A multicenter application and evaluation of the oxford classification of IgA nephropathy in adult chinese patients. Am J Kidney Dis. 2012;60(5):812-

\section{Submit your next manuscript to BioMed Central and we will help you at every step:}

- We accept pre-submission inquiries

- Our selector tool helps you to find the most relevant journal

- We provide round the clock customer support

- Convenient online submission

- Thorough peer review

- Inclusion in PubMed and all major indexing services

- Maximum visibility for your research

Submit your manuscript at www.biomedcentral.com/submit
) Biomed Central 